\title{
El proceso de representaciones sobre las FARC. 1964. \\ Los inicios*
}

\author{
Julián Penagos Carreño** \\ Recibido: 15 noviembre de 2012 - Aprobado: 23 de enero de 2013
}

\section{Resumen}

Este artículo presenta una parte de la investigación concerniente al proceso de construcción de representaciones en la prensa nacional e internacional sobre las Fuerzas Armadas Revolucionarias de Colombia-Ejército del Pueblo -FARC-EP-durante un periodo que comprende su inicio como grupo guerrillero en 1964 y su consolidación como un ejército que puso en vilo al Estado colombiano en 1996. Este ensayo se enfoca de manera exclusiva en el primer año de origen de esta guerrilla, enfáticamente en el año de 1964.

Palabras Clave: conflicto, representaciones, prensa, guerrilla, FARC, Marquetalia.

* El presente artículo es un fragmento de la Tesis de Maestría en Historia de la Universidad de los Andes "Representaciones del Conflicto Armado Colombiano en la prensa: 1964-1996). Adscrita al Grupo de Investigación en Periodismo (GIP) en la Línea de Investigación Comunicación y Conflicto. Institución Financiadora: Universidad de La Sabana.

** Magíster en Historia de la Universidad de Los Andes. Comunicador social de la Universidad Santo Tomás de Aquino. Docente de la Universidad de Los Andes. julianpc@unisabana.edu.co. 


\title{
Representation Process on FARC. 1964. The Beginning
}

\begin{abstract}
This article presents a part of the research related to the representation construction process in national and international press on "Fuerzas Armadas Revolucionarias de Colombia" - People army -FARC-EP- from its beginning as a guerrilla group in 1964 and its consolidation as an army which put in check Colombian state in 1996. This essay exclusively focuses in the first year of origin of this guerrilla group, especially in the year 1964 .
\end{abstract}

Key words: Conflict, representations, press, guerrilla, FARC, Marquetalia. 
... contra bandoleros y seres rebeldes y

Desnaturalizados, la única solución está

En el fuego eficaz de las armas...

Mayor General Ayerbe Chaux

(Meertens E Sánchez, 1983)

\section{Introducción}

Este artículo presenta una parte de la investigación concerniente al proceso de construcción de representaciones en la prensa nacional e internacional sobre las Fuerzas Armadas Revolucionarias de Colombia-Ejército del Pueblo -FARC-EP- durante un periodo que comprende su inicio como grupo guerrillero en 1964 y su consolidación como un ejército que puso en vilo al Estado colombiano en 1996. Este ensayo se enfoca de manera exclusiva en el primer año de origen de esta guerrilla, enfáticamente en el año de 1964.

En esta medida, el trabajo hace la pregunta: ¿Cuáles han sido las representaciones que pueden ser reconocidas en cuatro periódicos en el año de 1964, desde la información (noticia, crónica, reportaje) y la opinión (editorial, columnas de opinión), sobre las Fuerzas Armadas Revolucionarias -FARC-EP-?

Para dar cuenta del anterior interrogante, el conflicto armado colombiano es tomado aquí no solo como un fenómeno social, sino como un hecho que se ha construido simbólicamente a través de las narraciones y las imágenes que se transmiten y leen de él, que inciden en la comprensión o no del mismo, y es la prensa un escenario en donde se producen y reproducen todas estas significaciones que, incluso, pugnan entre sí (Barón EV Valencia, 2004). Por lo tanto, las representaciones ${ }^{1}$ son construcciones discursivas que "interactúan socialmente y configuran maneras de darle sentido a la existencia, universos de significación, referentes de identidad, patuas de reconocmiento sobre lo común y lo diverso, lo igual y lo diferente, consolidada en el tiempo a través de intercambios sociales y órdenes institucionales" (Bonilla E Raya , 1998, p. 20).

Por lo tanto, en primer lugar, se intentará demostrar que las representaciones son un proceso que con respecto a la prensa se da en tres niveles discursivos: bélico-militar, político y moral. El nivel discursivo bélico-militar, trata de los actos de guerra como

1 La Teoría de las Representaciones tiene una variada tradición disciplinar. Desde la psicología, se plantea que las Representaciones son construcciones mentales de la realidad (Moscovici, 1975). Por otro lado, Emile Durkheim expone el concepto de Representación Colectiva, como una construcción de la realidad entre los individuos y los medios con los que existe interacción. (Durkheim E Mauss, 1903). El historiador Roger Chartier en el libro "El Mundo como Representación" trabaja su historia cultural ligada más a los símbolos y a la circulación de los mismos, por esto su trabajo maneja el concepto de Representación Colectiva basado en Mauss y Durkheim en la que estudia tres polos: el estudio crítico de los textos, las formas de circulación de los mismos y el análisis de las prácticas de apropiación de estos textos en donde "se apoderan de los bienes simbólicos, produciendo así usos y significaciones diferenciadas" (Chartier, 1992, p. 50). En donde la representación colectiva se presenta de acuerdo a la relación o el encuentro del "mundo del texto" con el "mundo del lector" basado en Ricoeur. Este trabajo toma a la representación como una construcción semiótica de la realidad, solo haría énfasis en el "mundo del Texto" y no en el del lector, por eso la Representación como tal, no sería colectiva ni social. 
enfrentamientos, acciones de las FARC y operaciones militares. El nivel político hace referencia a la negociación, legislación, políticas de seguridad y valores ideológicos de la guerrilla. Por último, el nivel moral consta sobre el juzgamiento de las acciones por parte de los medios, ya sean correctas o incorrectas o malos y buenos.

En segundo lugar, los juicios de valor presentados en cada medio determinan la tipología de relación de poder entre los bandos en contienda, y pueden ser: de asimilación, de identificación o de neutralidad. La primera, cuando la prensa arguye que la guerrilla debe ser eliminada. De identificación cuando la misma afirma que debe ser entendida y se exponen y comprenden las intenciones del otro grupo, y de neutralidad, cuando se realiza una exposición de los hechos sin emitir ningún juicio; es una especie de indiferencia hacia el hecho o grupo.

En tercer lugar, el producto final de todo este proceso da como resultado una entidad histórica o representación de ese otro como enemigo, que estará relacionado con un nivel de relación axiológico (juicio de valor: malos/buenos), paraxiológico (someter o ser sometido) y el plano epistémico (conocer u ignorar al otro) y que dará como resultado la actitud mostrada frente al enemigo utilizando la teoría de los Spillman (1991)

Desconfianza: todo lo que proviene del enemigo es malo o, si parece razonable, obedece a razones fraudulentas. 2. Culpar al enemigo: el enemigo es responsable de las tensiones existentes y tiene la culpa de todo lo que es negativo en las circunstancias predominantes; 3 . Actitud negativa: todo lo que hace el enemigo es con intención de perjudicarnos; 4. Identificación con el mal: el enemigo encarna lo opuesto de lo que somos y de aquello por lo cual luchamos, quiere destruir lo que más estimamos y, por consiguiente, debe ser destruido; 5. Simplificación negativa: todo lo que beneficia al enemigo nos perjudica, y viceversa; 6. Negación de la individualidad: todo lo que pertenece a un grupo determinado es automáticamente nuestro enemigo; 7. Negación de la empatía: no tenemos nada en común con nuestro enemigo; los sentimientos humanos y los criterios éticos hacia el enemigo son peligrosos e imprudentes. (pp. 59-60).

\section{Metodología}

Este estudio realizó un análisis de contenido de una muestra de cuatro periódicos compuesta por El Tiempo, Voz Proletaria, El Espectador y El Siglo. Fueron tres los criterios para escoger la muestra: primero, diarios o revistas de cobertura internacional, nacional y regional con el objetivo de realizar comparaciones en los sistemas de representación. Segundo, diarios o revistas que han permanecido en el tiempo o que han desaparecido, para obtener una visión temporal de los sistemas de representación. Tercero, periódicos o revistas de oposición para obtener una perspectiva más amplia de las luchas de la significación en los sistemas de representación. La unidad de análisis de esta investigación es toda "información periodística"2 que aparezca en cada uno de los diarios que haga referencia de manera directa a las Fuerzas Revolucionarias de Colombia -FARC-EP-.

2 Se entiende por información periodística el texto que contiene: un titular (antetítulo, título y subtítulo) + un cuerpo informativo (que es la información que desarrolla ese titular) + unos recursos visuales Nota: no se tomaran las informaciones denominadas"breves", "rápidas", "cápsulas", "panorama noticioso" de los 
La coyuntura histórica escogida es la de mayo 27 de 1964, fecha de iniciación de la "Operación Marquetalia", considerado como el momento en que se da el inicio mítico del grupo guerrillero; el rastreo de notas periodísticas se realizó hasta 15 días después de la fecha fijada, y se encontraron 66 piezas. El análisis se realizará según los cinco niveles del análisis de discurso de prensa expuestos por Teún Van Dijk (1990): morfológico, sintáctico, semántico, pragmático y retórico.

\section{Año 1964: las repúblicas independientes}

Las representaciones que construye la prensa sobre las FARC-EP en 1964 se ven influenciadas por el contexto histórico latinoamericano, que por esos momentos, estaba inmerso en un discurso de lucha anticomunista comandado por Estados Unidos. El triunfo de la Revolución Cubana entre 1959 y 1960 hizo palpable la necesidad geopolítica de ese país por evitar una avanzada de las ideas de Lenin en la región, y lo llevó a formular políticas de prevenir y exterminar los focos revolucionarios que podrían desestabilizar a América Latina. Se lleva a cabo el plan LASO (Latin American Security Operation) que consiste en un plan operativo-táctico para contrarrestar los movimientos comunistas.

En Colombia, el plan LASO fue ejecutado durante el gobierno de Guillermo León Valencia (1962 1966) siendo General del ejército Alberto Ruiz Novoa veterano de la guerra de Corea. El ambiente político y social en el que se empiezan a construir las representaciones de las aún no nacidas FARC-EP estará encuadrado por la lucha del Gobierno en contra de los bandoleros que quedaron de la época de la Violencia. Sobre todo después de que en 1961 el Partido Comunista Colombiano, que había vuelto a ser declarado legal, declaró su intención de aplicar "todas las formas de lucha" para lo toma del poder, lo que en la práctica significó apoyar sindicatos en el ambiente urbano y grupos de autodefensa en las zonas rurales (Pecaut, 2008, pp. 30-35).

El presidente, del Partido Conservador, Guillermo León Valencia tomó la responsabilidad de "pacificar" a un país que había visto el fortalecimiento, durante el anterior período gubernamental, de unas zonas llamadas "repúblicas independientes" y de los "bandidos sociales" que habían quedado rezagados de la época de "La Violencia". Por lo tanto, en el cumplimiento del "poner fin a la violencia" inicia la aplicación de fuerza militar en contra de los grupos de "bandidos" de los años cincuenta y el desarrollo de la acciones cívico-militares con el propósito de "ganar la confianza de la población rural, sin la cual la verdadera pacificación era imposible" (Bushnell, 2007, p. 321)

En 1964, el Gobierno lleva a cabo una de las operaciones cívico-militares con más recordación en la historia del conflicto colombiano: la Operación Marquetalia. Esta operación se realiza entre mayo y junio de ese año con el propósito de cumplir las órdenes del Presidente de restablecer el orden público en estas regiones.

medios de comunicación seleccionados. Así mismo, se debe tener en cuenta que no se analizara la representación de las imágenes a menos que estén articuladas íntimamente con el texto. 
Las FARC-EP aún no existían como tales; eran una agrupación de hombres que venían peleando desde la época de La Violencia y que no se habían acogido a las políticas de armisticio de los gobiernos de Rojas Pinilla y Alberto Lleras Camargo, y que, además, habían resistido los continuos ataques a las zonas de influencia comunista como la Guerra de Villarrica entre 1955 y 1958. Y que después de tener una tradición de "colonización armada" y "columnas de marcha" se consideraron grupos de autodefensa campesina organizadas por el partido comunista (Pecaut, 2008, p. 23). Con la operación Marquetalia, el grupo se convierte en una guerrilla móvil, llamada Bloque o Frente Sur, y más tarde (en 1966), con la orientación más visible del Partido Comunista, se llamarán Fuerzas Armadas Revolucionarias de Colombia FARC ${ }^{3}$.

Pero entonces cqué es Marquetalia? Marquetalia es una zona ubicada en el departamento del Tolima cerca al municipio de Gaitania y el Nevado del Huila, bañado por los ríos Atá, y Sadaña y conformado por las poblaciones de Planadas, Santa Rita, Chapinero, Órganos, San Luis, Carmen de Palermo, San Miguel y la hacienda La Trigueña. A principios de los años 60 esta zona fue ocupada por los reductos de combatientes de la época de La Violencia.

Desde noviembre de 1961 la prensa y en específico el periódico conservador El Siglo construyen la representación de Marquetalia como una república independiente, utilizando como principal fuente a su principal editorialista el también conservador Álvaro Gómez Hurtado.

Para estos años se habla de 16 repúblicas independientes: Tequendama, Urabá, Vichada, Territorio Vásquez, El Duda, Ariari, Guayabero, Pato, Riochiquito y Marquetalia, entre otras ${ }^{4}$. A partir de la presión del senador conservador, el presidente Guillermo León Valencia decide atacar y acabar una a una con estas "repúblicas independientes".

A finales de mayo, para periódicos liberales como El Tiempo o El Espectador la discusión se encuadra, además, en acabar con los bandoleros que habían quedado de la época de

3 Marulanda citado en (Rochlin, 2003, p. 97) afirma que la guerrilla de las FARC se fundó en parte de debido al asesinato de Gaitán y al rompimiento de las promesas del Partido Liberal, que empujó a muchos campesinos a insertarse en los grupos de izquierda, donde se veía alguna opción para sobrevivir. Estos movimientos se dan entre los años cincuenta y sesenta, donde: "la movilización campesina inicia en el espacio de la hacienda y se va expandiendo a espacios de colonización a través de las columnas en marcha. El concepto de colonizaciones armadas alude a colonizaciones que se llevan a cabo bajo el control y orientaciones de grupos guerrilleros que constituyen contrapoderes locales revestidos de legalidad; grupos paraestatales" (Marulanda, 2003, p. 44). Según Ramírez (1990) la colonización es un proceso mediante el cual se integra "la tierra al proceso histórico de producción y mercado", solo que en Colombia, este proceso se dio a partir de la descomposición y éxodo del campesinado debido a La Violencia, lo que resulta en dinámicas de pleitos en donde se vinculan elementos armados y violentos al proceso. Según el autor, la colonización armada tiene un proceso en el que primero se expropia a los campesinos de la tierra y después algunos grupos toman las armas para defender o apropiarse de algunos terrenos. (Ramírez, 1990, pág. 65) El autor Germán Guzmán afirma "Parece que el comunismo quiso aprovechar la favorable coyuntura de La Violencia de 1949 y destacó emisarios a organizar "la guerrilla" con miras a capitalizar el conflicto, para asegurar un control absoluto del movimiento campesino" Citado en (Marulanda, 2003, p. 42)

4 El estudio de Adriana Marulanda sugiere que para la época en los debates en el congreso se llegó a hablar de hasta 16 repúblicas independientes. (2003, pág. 54) 


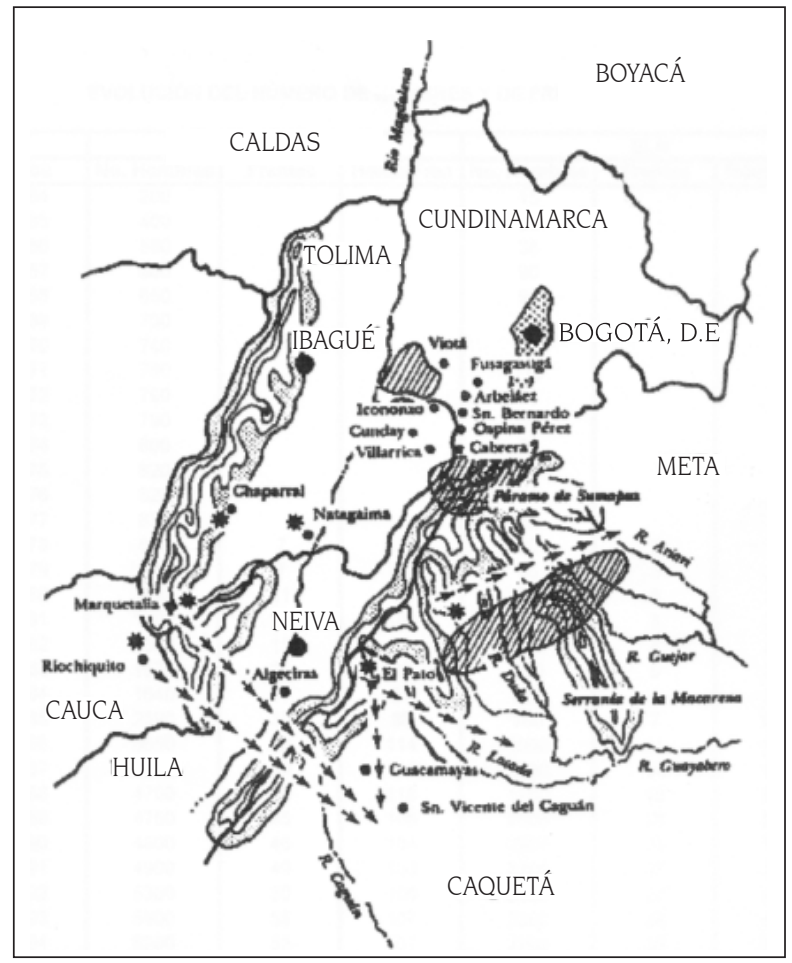

Gráfica 1. Repúblicas Independientes.

Fuente: Vélez (1999)

La Violencia, y que se convirtieron en antisociales y delincuentes que atacaban incluso a los de su mismo partido (El Tiempo, mayo 30, 1964). El periódico conservador El Siglo sugiere que el grupo de Marquetalia "Son forajidos o bandidos porque en la dictadura [la de Rojas Pinilla] quedaron fuera de la acción de los partidos" (El Siglo, mayo 21, 1964).

En los artículos de estos periódicos, acabar con la región de Marquetalia significaba la "eliminación del bandolero en potencia" (El Tiempo, mayo 31, 1964) y la restauración del imperio del orden (El Espectador, mayo 6, 1964). Es común encontrar artículos que reseñan la muerte o entrega de bandidos como Tarzán, Sangrenegra junto con reseñas "heroicas" del Batallón Colombia listo para entrar en acción para "pacificar" la "zona invadida de bandoleros" y recuperar la soberanía nacional (El Tiempo, mayo 31, 1964).

En junio 9 de 1964, el periódico El Tiempo también insistía en dejar de llamar a estas zonas Repúblicas Independientes debido a la mala imagen que le daban al país en el exterior:

No es inoportuno reflexionar un poco sobre el nombre de repúblicas independientes, que se ha venido dando en los últimos tiempos a las comarcas nacionales ocupadas por cuadrillas de bandoleros. Pudo ser explicable esa clasificación en momentos de intensa preocupación y aun angustia nacional, por lo que sucedía en esas regiones. 
Pero hay que convenir ahora que no es exacta, ni oportuna; ni le sirve al país para la pacificación en marcha, ni para la consolidación de su prestigio en el exterior. En Colombia no hubo, ni nunca habrá repúblicas independientes (El Tiempo, junio 9, 1964).

\section{Los tipos discursivos de la representación: bandidos, guerrilla comunista o resistencia campesina}

Tabla 1. Representaciones en la Prensa 1964

\begin{tabular}{|l|l|l|l|c|l|}
\hline \multicolumn{1}{|c|}{ Periódico } & $\begin{array}{c}\text { Nivel del Dis- } \\
\text { curso }\end{array}$ & $\begin{array}{c}\text { Niveles de } \\
\text { Relación }\end{array}$ & $\begin{array}{c}\text { Tipología de } \\
\text { Relación }\end{array}$ & $\begin{array}{c}\text { Actitud } \\
\text { Frente al } \\
\text { Enemigo }\end{array}$ & \multicolumn{1}{|c|}{ Representación } \\
\hline El Tiempo & Bélico - Militar & Paraxiológico & Asimilación & $4,5,6$ & Bandido /Bandolero \\
\hline El Espectador & Bélico - Militar & Paraxiológico & Asimilación & $4,5,6$ & Bandido /Bandolero \\
\hline El Siglo & Bélico - Militar & Paraxiológico & Asimilación & $4,5,6$ & Bandido /Bandolero \\
\hline Voz Proletaria & Moral & Axiológico & Identificación & 7 & Resistencia Campesina \\
\hline
\end{tabular}

Como se puede ver en la tabla 1, la mayoría de los periódicos analizados de esta época están a favor de la operación de Marquetalia. Las piezas periodísticas se caracterizan por tener un discurso belicista, cuyo nivel de relación sería paraxiológico o sea el de someter al otro por medio de la asimilación violenta; su actitud frente a este enemigo sería:

4. Identificación con el mal, el enemigo encarna lo opuesto de lo que somos y de aquello por lo cual luchamos, quiere destruir lo que más estimamos, y por consiguiente debe ser destruido; 5. Simplificación negativa todo lo que beneficia al enemigo nos perjudica y viceversa; 6 . Negación de la individualidad, todo lo que pertenece a un grupo determinado es automáticamente nuestro enemigo (Spillman \& Spillman, 1991, pp. 59-60).

Ejemplo de este discurso bélico-militar de asimilación es una crónica del 4 de mayo de 1964, de Álvaro García: aparecida en el periódico liberal de El Espectador, afirmaba que el bandolero Tirofijo tenía asolada a la población por medio de intimidaciones y que este amenazaba a los campesinos si no lo ayudaban.

El Tiempo, El Espectador y El Siglo son periódicos en los que se ejemplifica este discurso bélico militar, paraxiológico y asimilativo. El 9 de mayo de 1964, el Gobierno anunciaba con vehemencia, hablando en nombre del Frente Nacional, la lucha en contra de la "tiranía" de los criminales que comandan las Repúblicas Independientes (El Espectador, mayo 9, 1964). Pero también anuncia que "Se respetará la vida de los bandoleros que se entreguen, dice la VI Brigada" (El Espectador, mayo 6, 1964). El periódico conservador El Siglo publicaba una noticia el 12 de mayo en la que se demostraba la maldad de la "banda de Tirofijo" (El Siglo, mayo 12, 1964) al asesinar al inspector de policía del municipio cercano de Órganos. 


\subsection{Demonizar al enemigo}

Una de las estrategias discursivas más comunes en la construcción de la representación como bandido es la de demonizar al enemigo. Por ejemplo, El Tiempo reseña el 28 de mayo, unos comentarios realizadas por Tirofijo sobre la operación diciendo que "no tolerará operación militar en sus dominios" (mayo 28, 1964). Por otro lado exacerba la parte violenta del conflicto, con noticias sin confirmación sobre actos presuntamente realizados por la "banda de Tirofijo".

El Siglo sugiere en el artículo fechado el 4 de junio de 1964 que Tirofijo había establecido la pena de muerte en la Región de Marquetalia: "Todo campesino que no le auxilie o encubra será muerto por sus hombres. El bandolero tiene minada una extensa zona del sur del Huila" (junio 4, 1964).

El Espectador, en un artículo fechado el 19 de mayo de 1964, justifica el uso de la fuerza: "Marquetalia será la recuperación pacífica pero respaldada por la fuerza como tantas veces lo necesita la paz de un territorio colombiano". El Tiempo emite una noticia sobre la gran cantidad de hombres que puede movilizar Marulanda, y lo describe como un personaje que manipuló fácilmente a los campesinos de la zona: "Los campesinos de Marquetalia fueron fáciles objetivos del proselitismo demagógico de un jefe guerrillero comunista que, en 1961, se impuso a los líderes liberales. Pedro Antonio Marín de 34 años, alias Tirofijo o Marulanda, domina con solo 200 hombres, toda esta vasta zona. Dominio por la fuerza o por la persuasión" (junio 6, 1964).

En este contexto la zona de Marquetalia es descrita como una vasta zona rural sin Dios y sin Ley, apta como guarida de los bandoleros que quedaron de la "primera violencia". En este marco de interpretación, la operación se convierte en una maniobra de liberación, en una segunda independencia. (El Tiempo, junio 6, 1964).

Entre tanto, mientras se demoniza al enemigo, se reseñan las obras cívicas de los soldados en la zona. Se muestran campesinos sonrientes en lo que los periódicos llamaron penetración psicológica (El Tiempo, junio 6, 1964). O se publican reportajes en donde los campesinos dicen ser amigos de las Fuerzas Militares y bendicen su aparición (El Espectador, mayo 64 de 1964) y "Se critica a los sectores de opinión que dicen que esta operación se está llevando a cabo con armas. Se dice que se trata al campesino como un hermano. Que las armas solo se utilizarán si es necesario y que hasta el momento no se ha dado un solo tiro" (mayo 25, 1964). El Siglo sugiere, citando al general Ruiz Novoa, que los campesinos esperan la presencia del ejército para" liberarse de la tiranía de Tirofijo" (mayo 23, 1964).

\subsection{La representación de los combates y su relación con la lucha contra el co- munismo}

A finales de mayo y comienzos de junio del 64, cuando empiezan las confrontaciones, los medios oficiales se convierten en simples cajas de resonancia de los comunicados oficiales, y reseñan número de muertos, heridos y porcentaje de territorio tomado (El Espectador,

Anagramas Volumen 11, № 22 pp. 145-162 ISSN 1692-2522 Enero-Junio de 2013. 212 p. Medellín, Colombia 
junio 3, 4 y 5, 1964). El periódico El Tiempo reseña el $1^{\circ}$ junio las primeras cifras del operativo: "bandoleros muertos 47, bandoleros capturados 126, civiles 70, soldados muertos 10".

Por otro lado, empiezan los rumores de la muerte de los dirigentes de los grupos. En algunas ocasiones, los periódicos pregonan la muerte de Tirofijo (El Siglo, mayo 27, 1964) en otras la del dirigente de El Pato, alias Richard: "Las tropas informan dominar ya el $75 \mathrm{x}$ 100 de la zona. Rumores en Ibagué informan sobre la muerte del "Mayor Richard" jefe de la zona del El Pato. Dos soldados han sido heridos durante los encuentros" (junio 3, 1964).

En este momento, los periódicos, empiezan a deplorar la forma de combate de los "bandidos". Por ejemplo, el 4 de junio el periódico El Tiempo los tilda de cobardes e infames, pues combaten en emboscadas (atacan y huyen) se les caracteriza como los "enemigos de la patria" (El Tiempo, junio 4, 1964).

La pregunta que se puede hacer aquí es si estamos en un ambiente de lucha contra el comunismo ¿Por qué son escasos los artículos que hacen referencia a las FARC como guerrilleros? Los periódicos El Tiempo, El Espectador y El Siglo hablan de bandidos/ bandoleros y no de guerrilleros. La razón de esto es que para ese entonces, la palabra guerrilla-guerrillero estaba emparentada con "los partidos tradicionales en su rivalidad por el poder" (Pecaut, 2008, p. 24). Por lo tanto, el término guerrilla estaba necesariamente relacionado con los movimientos de "oposición social o política" (Pecaut, 2008, p. 24) que se manifestaba en guerrillas locales de autodefensa entre los años de 1946 y 1953. Al surgir el Frente Nacional, la rivalidad entre los dos partidos se consideraba finalizada; por lo tanto, estos grupos que no se habían acogido a ninguna amnistía o rendición no eran considerados guerrilleros, sino grupos de bandas al margen de la ley que habían sido influidos por grupos comunistas. Es decir, estos periódicos desconocen por completo sus antecedentes en las guerrillas liberales de la época de La Violencia. Los periódicos pro-gobiernistas colombianos reflejan así el clima de olvido reinante en la sociedad colombiana como forma de "dejar atrás" ese pasado tan incómodo, debido a que, como afirma Pecaut, la pacificación y la paz solo eran posibles: "... gracias a un pacto de silencio entre los partidos sobre sus responsabilidades en lo que acababa de ocurrir. La Iglesia otorga su aval para que se olviden las suyas. Queda así más que proscrita la elaboración simbólica e histórica de La Violencia" (2008, p. 34).

Sin embargo, estos periódicos hacen continuas referencias a la conexión del grupo de Marquetalia con el Partido Comunista. Son tres las formas como se presenta esta conexión. Primera, el periódico El Siglo en un artículo del 4 de junio de 1964 afirma que la dependencia se da en el nivel local por su relación económica y organizativa con el Partido Comunista: "350 mil pesos recolectados por los comunistas para enviar a Marquetalia". El diario El Espectador ya había dicho en un artículo del 19 de mayo de 1964 que son "antisociales que han impuesto el discurso comunista internacional contra las leyes de la república", en donde, según El Siglo tres días después, el ejército tenía que "liberar la región del imperio comunista de Tirofijo" (1964, mayo 21).

Por otro lado, tenemos una relación por similitud en torno a eventos que también tienen un significado particular en la guerra comunista. El periódico El Siglo relaciona 
para el 27 de mayo de 1964, Marquetalia con Cuba y afirman que los comunistas querían "fundar allí su Sierra Maestra". La fuerza de esta afirmación es letal, se sabe que Fidel Castro organizó las operaciones de la Revolución cubana desde esta zona montañosa; por lo tanto, la similitud conllevaba una amenaza a que Tirofijo pudiera hacer lo mismo en Colombia desde Marquetalia.

Una tercera es la vinculación directa de los grupos de Marquetalia con la Unión Soviética y Cuba. El Espectador sugiere el 28 de mayo de 1964, que "Isauro Yosa ha viajado a Cuba y Rusia y es el que imparte la educación comunista a las tropas".

Los grupos de Marquetalia eran continuamente llamados tropas rebeldes de izquierda relacionadas con el Bloque Soviético bajo el mando del Gobierno cubano con el propósito de tomarse el poder. Los términos usuales para referirse a la guerrilla son: insurgentes, grupos de izquierda o grupos rebeldes.

\title{
3.3. La representación "Resistencia Campesina"
}

En contraposición a estos esquemas de representación, el periódico de izquierda Voz Proletaria construye la significación del grupo armado validando sus orígenes agrarios y reconociendo Marquetalia como una zona de desmovilizados de las guerrillas liberales o comunes. Jaime Guaraca, miembro de las FARC dice al respecto:

Acordamos también que se eliminarán todos los grados militares o que quedaran suspendidos; que la gentes se ponía a trabajar y el que quisiera quedarse a trabajar en la región lo podía hacer y el que quisiera irse se podía ir para su lugar de origen; los bienes del movimiento, que estaban representados en un ganado y otros animales, se distribuyeron a la gente; la conferencia tomó como conclusión distribuir la tierra, porque en Marquetalia eran terrenos baldíos (Marulanda, 2003, p. 56).

Es decir, el periódico de izquierda reconoce las raíces agrarias del movimiento campesino que resistió la "agresión oficial". El 13 de junio de 1964 el periódico publica:

\begin{abstract}
El Movimiento Agrario de río Chiquito y norte del Cauca, que como otros movimientos campesinos de Colombia, luchan por la paz y la tranquilidad manifiesta ante la opinión pública y con especialidad a los sectores populares y revolucionarios que luchan contra el llamado "frente nacional", que se viene realizando una soterrada política de engaño y confusión de las masas, por parte de los altos círculos gobernantes, civiles y militares, tendiente a hacernos aparecer a los habitantes de esta "república independiente" • fuera de los planes criminales fraguados contra el campesinado y que en estos días han comenzado a desarrollarse hostilizando con el aparato represivo del Estado a la región de Marquetalia (Voz Proletaria, 1964, junio 13).
\end{abstract}

Sin embargo, existe cierta instrumentalización de la Operación Marquetalia en contra del Frente Nacional. Esto puede ser debido a que Voz Proletaria es la herramienta de vocería del Partido Comunista. Este partido quedó marginado obligatoriamente de participar políticamente en el Gobierno debido a que el proyecto de Frente Nacional solo incluyó a los partidos tradicionales Liberal y Conservador. Al respecto dice Bushnell "Para algunos observadores externos, así como para una minoría desafecta de colombianos, las nuevas reglas representaban, por su propia naturaleza, una negación de los principios democráti- 
cos" (2007, p. 318). Por lo tanto, el discurso que maneja este periódico está dentro de un nivel moral que maneja la dicotomía de malos / buenos. Esto implica una identificación con la causa del grupo de Marquetalia (los buenos) y un rechazo de las tácticas del Gobierno (los malos). Este esquema de representación refleja lo que después se convertirá en el mito heroico de fundación de las FARC-EP, ya que tiene un alto contenido histórico, pues recuerda como antecedentes a las autodefensas liberales de la época de La Violencia y las coloca dentro del ámbito de una resistencia eterna. Lo describe primero como una lucha en contra del intento de exterminio del Partido Conservador, y ahora como una "lucha contra el Frente Nacional":

Nuestro delito es la rebeldía que a partir de 1948 nos llevó a la lucha guerrillera para defendernos de las hordas chulavitas; nuestro delito es el trabajo; nuestro delito es no ser adictos al gobierno; nuestro delito es no ser frente nacionalistas; nuestro delito es no estar al servicio de este gobierno traidor que vende nuestra soberanía e hipoteca el país, prostituye la justicia y somete al pueblo colombiano al hambre, la miseria y el desempleo, habla y practica la política de los más bajos sueldos y salarios -porque una modesta alza dizque produce la inflación según el propio presidente Valenciacercena las libertades públicas y se lanza por los atajos de la dictadura militar (Voz Proletaria, 1964, mayo 28).

Esta identificación con el grupo de Marquetalia lleva al periódico a emprender una lucha en contra de la construcción significativa de los Movimientos Agrarios como Repúblicas Independientes, calificándola de ser una forma de criminalizar a los grupos de campesinos que habitan y trabajan en esta región. La consideran calumniosa y dañina para el entendimiento del conflicto por parte de la opinión pública: "Entendemos, señor Presidente, que se está utilizando la calumnia contra los campesinos como el llamarlos "repúblicas independientes" o el de que los moradores son bandoleros y criminales, cosa esta absurda y mentirosa..." (Voz Proletaria, 1964, Mayo 28).

\section{Las luchas de la significación sobre la Operación Marquetalia}

En este clima de contradicciones entre calificar el grupo de Marquetalia, ya sea como comunistas con conexiones con Cuba y la Unión Soviética o como campesinos que conforman movimientos agrarios, va de la mano con la lucha por significar la misma operación del ejército. Entramos en el terreno de la relación entre ese "nosotros" y el "ellos" que se muestra en los periódicos como un proceso que no se da en un solo sentido sino que continuamente se construye y deconstruye a partir de lo que los unos dicen de los otros y viceversa, y que hace parte de una de las características generales de las representaciones sobre el conflicto: la dificultad para entender lo que pasó en realidad.

Es así como la Operación Cívico Militar ${ }^{5}$ fue calificada por los periódicos progobiernistas como un operativo pacífico de restauración y por los periódicos alternativos/ críticos como una agresión oficial en la cual estaban involucrados los "yanquis". Los debates de significación se dan en torno a si la zona fue bombardeada o no, a que si hubo violencia

5 "Según Germán Guzmán Campos el plan Cívico Militar "Comprende varias etapas: Primera, guerra sicológica, mediante la acción cívico militar con miras a ayudar a los campesinos para ganarse sus simpatías, 
oficial desde el principio o no, a que si Estados Unidos estaba involucrado, a que si Cuba estaba enviando dinero y armas, a que si existió una guerra bacteriológica o no, que si Marulanda tenía mil hombres, o 2 mil o solo 200 o 48. Que si el ejército atacó con 16 mil soldados entre ellos aerotransportados o solo con 3 mil. En fin, una serie aspectos que a cualquiera le haría difícil entender qué era lo que estaba sucediendo.

Por ejemplo, el periódico liberal El Tiempo se apresura a desmentir el uso de la fuerza en un artículo fechado el 4 de junio. Dos días después, El Siglo anuncia que el ejército dice que nunca se ha utilizado La Violencia en la operación (1964, junio 6). El 13 de junio, Voz Proletaria publica un artículo donde reseña el número de los bombardeos, sin dejar de lado la exacerbación de la alta moral de lucha campesina: "bárbaro bombardeo y ametrallamiento... mortíferos cohetes... Sanguinario bombardeo... Guerra bacteriológica. Persecución y asesinatos masivos (1964, junio 13).

De manera paralela, para finales de mayo del 64 surge el debate relacionado con la relación entre la operación y la ayuda internacional. La discusión se contextualiza en la Guerra Fría. Para el día 27 del mismo mes, el periódico conservador El Siglo reseña la relación comprobada entre el grupo de Marquetalia y Cuba: "Está comprobada la introducción de armas de contrabando, dice el ministro Gómez Martínez. Amplia investigación, adelantan el DAS y las Aduanas. Colombia pediría aplicación del tratado de Río si se comprueba que Castro envía armas" (1964, mayo 27).

Voz Proletaria responde al día siguiente con la denuncia de la intromisión de tropas norteamericanas en la operación de Marquetalia. La ayuda, según el periódico de izquierda, se da en los siguientes aspectos: guerra psicológica y campos de entrenamiento para tácticas de antiguerrilla (1964, mayo 28). Incluso, el periódico expone antecedentes históricos sobre esta supuesta intromisión:

Desde 1952 Colombia sufre la intromisión del ejército norteamericano... Guerra psicológica, propaganda negra... Las tropas norteamericanas dirigieron las operaciones de Villarrica... Artículo $5^{\circ}$ del pacto dice: obligación de Colombia de permitir la misión militar yanqui. Colombia se compromete a pagar la manutención de las tropas. Comisión del FBI vino a coordinar la misión anticomunista (1964, mayo 28).

Sobre las denuncias de Voz Proletaria de la presencia norteamericana en la operación Marquetalia, El Siglo había dicho ocho días antes que: "Manifiesta el general Gabriel Rebeiz Pizarro al rechazar informaciones sobre ayuda del exterior en hombres para combatir La Violencia. No hay unidades de fuerzas especializadas norteamericanas en nuestro territorio. Es diferente la situación en el Viet Nam del sur a la de Colombia" (1964, mayo 22).

reclutar adeptos y formar grupos de espionaje y delatores de quienes estén en desacuerdo con el gobierno, labor secundada por la "Acción Comunal" y los "Cuerpos de paz" y por las instituciones de socorro USA como la Care y la Cáritas norteamericanas. Es el período durante el cual el ejército hace cálculos logísticos y planea acciones de guerra". (Marulanda, 2003, p. 55) 
Siguiendo esta línea de reflexión, a mediados de junio los periódicos se caracterizan por un triunfalismo visible. Para El Espectador y El Tiempo, que continúan reproduciendo comunicados oficiales, la operación fue un éxito total. El Siglo anuncia "Libertada Marquetalia" y sugiere que: "El ejército se tomó el cuartel general de "Tirofijo". En la acción participó la fuerza aérea. Al huir, los bandoleros incendiaron tres casas donde tenían su armamento. Herido un suboficial en acción" (1964, junio 15).

Estos debates, reflejados en la prensa de la época, aún son motivo de discordia y confusión. Ferro y Uribe (2002) reseñan en parte la lucha entre el Mito de Marquetalia según las FARC y la "propaganda negra" según las fuentes oficiales. Por ejemplo, en una entrevista hecha a Simón Trinidad, este afirma que:

El hecho fundamental y que divide una primera de una segunda y definitiva es Marquetalia. En Marquetalia, hay una guerrilla que es el núcleo inicial de hombres que están ya separados de sus familias, están enguerrillerados, viven en el monte... Viene luego el ataque a Marquetalia donde había un asentamiento de estos campesinos que con armas se enfrentaban al régimen de ese momento. El ataque a Marquetalia tiene varias partes que van a definir lo que es la consolidación de un movimiento guerrillero....uno; el apoyo directo del Partido Comunista con el envío de Jacobo Arenas y Hernando González... Dos, este núcleo campesino resistente en Marquetalia define algo que van a ser definitivo, ampliar la lucha guerrillera en todo el país y buscar una unidad entre esta Vanguardia guerrillera y el pueblo colombiano (Ferro \& Uribe, 2002, p. 27).

Una página después, los autores reseñan una columna del general Álvaro Valencia Tovar del periódico El Tiempo de enero 15 de 1999: "No se arremetió contra Marquetalia con los 16.000 hombres de la leyenda negra. Se emplearon tres batallones (1.500 hombres) que ocuparon las zonas circunvecinas para sustraerlas del influjo del patriarca, mientas una fracción de infantería..." (Ferro E Uribe, 2002, p. 28). Dice el dirigente comunista Alberto Vieira (director de Voz Proletaria) sobre esta operación: "fue una maniobra de cerco y penetración en esa zona, a fin de tomar posiciones para lanzar un golpe sorpresivo destinado a aniquilar la agrupación armada de autodefensa campesina" (Marulanda, 2003, p. 55).

Así las cosas, tenemos dos tipos de representación, los periódicos pro gobiernistas para quienes los de Marquetalia son un grupo de bandidos al margen de la ley, y los opositores, quienes los veían como movimientos agrarios que resistían los embates de la oligarquía. Estas representaciones entrarían, en los años siguientes, por un proceso de transición rumbo a una politización relacionada con el panorama mundial bipolar reinante.

\section{Conclusión}

En este trabajo se ha expuesto una relación entre el discurso, los medios y las representaciones. El proceso puede relatarse de la siguiente manera: la realidad se deconstruye y construye por medio del lenguaje que conforman discursos con una intención (sea política o no); estos discursos circulan en los medios de comunicación y se legitiman en ellos a raíz de la mediación cognitiva, propiedad intrínseca de estos. Al ser legitimados los discursos, se convierten en representaciones de la realidad buscando el consenso social; cuando una representación permanece en el tiempo y es aceptada socialmente se instala en el nivel 
de categoría histórica. Transversalmente a este proceso, intervienen los mecanismos de apropiación y los esquemas culturales e históricos como determinantes de producción del discurso. Por lo tanto, este proceso de construcción de representaciones es, por un lado, político, debido a los intereses particulares que intervienen y que tienen en los grupos de presión (instituciones políticas, religiosas, del gobierno, grupos armados, delincuentes etc.) su mayor agente de transformación; por otro lado, es un proceso cultural, debido a que, primero, ve el conflicto como un hecho social que se construye semióticamente y, segundo, porque expone discursos y los lleva al escenario de las luchas por la significación y el sentido de un acontecimiento o sujeto.

Teniendo en cuenta esto, se puede decir que el proceso de construcción de las representaciones en la prensa sobre las FARC-EP es un sistema de representación binario, en el que se identifica un "nosotros" y un "ellos" en función de la identificación de un enemigo eterno. Este sistema de representación binario, se puede identificar como una categoría histórica, ya que tiene una continuidad histórica y está aceptado socialmente para caracterizar y referir los grupos que hacen parte del fenómeno social conflicto armado y el grupo FARC-EP. Pero es categoría histórica no solo porque tiene una continuidad en la explicación de este fenómeno, sino porque también es utilizado para explicar otros que no son necesariamente de la misma índole.

\section{Bibliografía}

Bonilla , J., E Raya , M. (1998). Los discursos del conflicto. espacio público, paros cívicos, y prensa en Colombia. Bogotá: Cuadernos de Comunicación 35. Pontifica Universidad Javeriana.

Bushnell, D. (2007). Colombia: una nación a pesar de sí misma. Bogotá, Colombia: Planeta.

Chartier, R. (1992). El mundo como representación. Historia cultural: entre práctica y representación. Barcelona: Gedisa Editorial.

Durkheim, E. y Mauss, M. (1903) "De vuelque formes de classfication. Contribution á I'étude des représentations collectives". Anné Sociologique. COMPLETE

El Espectador. (12 de junio de 1964). Por entre trochas buscan a Tirofijo. El Espectador .

El Espectador. (13 de junio de 1964). Se respeterá la vida de los bandoleros que se entreguen, dice la VI Brigada. El Espectador.

El Espectador. (15 de junio de 1964). El Ejército ocupó a Marquetalia. El Espectador.

El Espectador. (16 de junio de 1964f). Operación final en Marquetalia. El Espectador.

El Espectador. (17 de junio de 1964). La Operación Marquetalia. Desesperada resistencia opone Tirofijo. Heridos 5 soldados. El Espectador.

El Espectador. (18 de mayo de 1964). Pacificación total del Tolima: Mingobierno. El Espectador.

El Espectador. (19 de junio de 1964). Libertad y protección ofreció Ruiz Novoa ayer a Marquetalia. El Espectador.

El Espectador. (19 de mayo de 1964). Con 3 mil soldados se inició anoche la Operación Militar de Marquetalia. El Espectador.

El Espectador. (19 de mayo de 1964). Sin retaliaciones. El Espectador. 
El Espectador. (2 de mayo de 1964). La Operación Marquetalia. Por miedo ayudan a Tirofijo. El Espectador.

El Espectador. (21 de mayo de 1964). El exterminio de la violencia en Colombia Ejército de Estados Unidos revela participación. El Espectador.

El Espectador. (22 de mayo de 1964). En Colombia no hay ni habrá tropas de E. U. El Espectador.

El Espectador. (23 de mayo de 1964). Dos operaciones adelanta Ejército en Marquetalia. El Espectador.

El Espectador. (24 de mayo de 1964). 5 días de Operación Marquetalia. El Espectador.

El Espectador. (25 de mayo de 1964). Cómo se adelanta la Operación Marquetalia. El Espectador.

El Espectador. (28 de mayo de 1964). La Operación Marquetalia: revelados sistemas de Tirofijo. El Espectador.

El Espectador. (3 de junio de 1964). Primeros contactos en Marquetalia: 2 heridos. El Espectador.

El Espectador. (30 de mayo de 1964). La Operación Marquetalia (IV) El Pato, región azotada por la violencia. El Espectador.

El Espectador. (4 de junio de 1964). La hora cero en Marquetalia. Emboscadas, campos minados y pena de muerte, encuentra el Ejército. El Espectador.

El Espectador. (4 de junio de 1964). Operación Marquetalia. El Espectador.

El Espectador. (4 de mayo de 1964). Pacíficamente avanza la Operación Marquetalia. El Espectador.

El Espectador. (6 de mayo de 1964). Parte de normalidad en el norte del Tolima. El Espectador.

El Espectador. (9 de mayo de 1964). Habla el Presidente Valencia "El gobierno dara la gran batalla en las repúblicas independientes". El Espectador.

El Siglo. (12 de junio de 1964). El restablecimiento de la Ley está próximo en Marquetalia. El Siglo .

El Siglo. (12 de junio de 1964). Tirofijo había prometido a los campesinos que el Ejército arrasaría a Marquetalia. El Siglo.

El Siglo. (12 de mayo de 1964). La banda de Tirofijo Asesinó al Inspector de Policía de "Órganos". El Siglo.

El Siglo. (13 de mayo de 1964). Colombia estudia intervención de Castro en asuntos internos. El Siglo.

El Siglo. (15 de junio de 1964). Libertada Marquetalia. El siglo.

El Siglo. (16 de junio de 1964). Tres militares muertos, 11 heridos y 14 malhechores eliminados en 25 días de la operación Marquetalia. El Siglo.

El Siglo. (18 de mayo de 1964). Cuando Iniciamos Este gobierno los bandoleros estaban en las gradas del capitolio, dice Valencia. El Siglo.

El Siglo. (22 de mayo de 1964). El ejército de Colombia es capaz de defender la soberanía de toda la nación con sus propias manos. El Siglo.

El Siglo. (22 de mayo de 1964). Ruiz Novoa y Fajardo Pinzón en Marquetalia. El Siglo.

El Siglo. (24 de mayo de 1964). Las gentes de Marquetalia esperan la acción del Ejército para liberarse de la tiranía de Tirofijo, dice Ruiz. el Siglo.

El siglo. (24 de mayo de 1964). Represión y violencia. El Siglo .

El Siglo. (26 de agosto de 1964). Vasta ofensiva contra las FARC. El Siglo. 
El Siglo. (27 de mayo de 1964). El comunismo no combatirá al ejército sino que buscará un nuevo refugio en otra zona. El Siglo.

El Siglo. (27 de mayo de 1964). Intenciones del Ejército en la zona de Marquetalia. El Siglo .

El Siglo. (27 de mayo de 1964). Mapa de las repúblicas independientes. El Siglo.

El Siglo. (3 de junio de 1964). El ejército inició combates con las bandas de Marquetalia. El Siglo.

El Siglo. (4 de junio de 1964). "Tiro fijo" estableció la pena de muerte en la región de Marquetalia. El Siglo.

El Siglo. (4 de junio de 1964). 350 mil pesos recolectados por los comunistas para enviar a Marquetalia. El Siglo.

El Siglo. (6 de junio de 1964). Dos bandoleros eliminados y un soldado herido en contacto en Marquetalia. El Siglo.

El Siglo. (6 de junio de 1964). No será bombardeada la región de Marquetalia. El Siglo.

El Tiempo. (1 de junio de 1964). Asalto en Corinto, Cauca. el Tiempo.

El Tiempo. (1 de junio de 1964). El Batallón Colombia, motor de la pacificación. El Tiempo.

El Tiempo. (25 de junio de 1964). Misterioso avión voló sobre Marquetalia. El Tiempo.

El Tiempo. (28 de mayo de 1964). Mensaje de Tirofijo a las Autoridades. El Tiempo.

El Tiempo. (29 de junio de 1964). La biblioteca de Marquetalia. El Tiempo.

El Tiempo. (3 de junio de 1964). Operación Marquetalia, Abiertas las acciones. El Tiempo.

El Tiempo. (31 de mayo de 1064). Eliminación del bandolero en potencia. El Tiempo.

El Tiempo. (1 de junio de 1964). Plan socioeconómico para frustrar bandas. El Tiempo.

El Tiempo. (4 de junio de 1964). Operación Marquetalia. TiroFijo combate al Ejército en emboscadas. El Tiempo.

El Tiempo. (6 de junio de 1964). Falsa una versión sobre bombardeo. El Tiempo.

El Tiempo. (6 de junio de 1964). Mil hombres puede movilizar Tirofijo. El Tiempo.

El Tiempo. (8 de junio de 1964). Marquetlaia en pie de guerra y en pie de paz. El Tiempo.

El Tiempo. (9 de junio de 1964). Pugna entre los jefes comunistas. El Tiempo.

El Tiempo. (9 de junio de 1964). Repúblicas independientes. El Tiempo.

El Tiempo. (mayo de 31 de 1964). El Pato, otra república independiente, de Richard. El Tiempo.

Ferro, Juan Guillermo; Uribe Graciela. (2002). El orden de la guerra. Las Farc-EP: entre la organización y la política. Bogotá: CEJA.

Marulanda, A. (2003). La cuestión agraria y su incidencia en los orígenes de las FARC-EP. Bogotá: Documento N. ${ }^{\circ}$ 58. Centro de Estudos Socioculturales e Internacionales CESO.

Meertens, D., E Sánchez, G. (1983). Revista del Ejército, Vol. VI. N. 24, marzo de 1966. Bogotá, Colombia: El Áncora.

Moscovici, S. (1975). Introducción a la Psicología Social. Barcelona: Editorial Planeta.

Pecaut, D. (2008). Las Farc ¿Una guerrilla sin fin o sin fines? Bogotá: Norma. 
Ramirez Tobón, W. (1990). Estado, violencia y democracia. Bogotá: Tercer Mundo Editores.

Rochlin, J. (2003). Vanguard Revolutionaires in Latin America. London: Lynne Rienner.

Spillman, K., E Spillman, K. (1991). La imagen del enemigo y la escalada de los conflictos. Revista Internacional de Ciencias Sociales, 59-77.

Van Dijk, T. (1990). La Noticia como discurso. Buenos Aires: Paidós Comunicaciones

Vélez, M. A. (1999). FARC-ELN. Expansión geográfica. Tesis de Grado. Bogotá. Universidad de los Andes.

Voz Proletaria. (13 de junio de 1964). Combatir los efectos de la guerra bacteriana solicitan los combatientes a la Cruz Roja. Voz Proletaria.

Voz Proletaria. (13 de junio de 1964). Crecen la Protesta y la solidaridad de los Guerrilleros de Marquetalia. Voz Proletaria.

Voz Proletaria. (13 de junio de 1964). Cuarto Bombardeo en Marquetalia. Voz Proletaria.

Voz Proletaria. (13 de junio de 1964). El pueblo no vuelva atrás, marcha siempre adelante. Voz Proletaria.

Voz Proletaria. (28 de mayo de 1964). "La Próxima legislatura le pedirá cuentas al gobierno". Pronostica Camilo Aluma en reportaje para Voz. Voz Proletaria.

Voz Proletaria. (28 de mayo de 1964). Declaración del Partido Comunista: iA la lucha contra la Intervención Yanqu! Voz Proletaria.

Voz Proletaria. (28 de mayo de 1964). Extinguir a campesinos que no respaldadn política del Gobierno se pretende. Voz Proletaria.

Voz Proletaria. (28 de mayo de 1964). Gran concentración popular dio apoyo a Marquetalia en Medellín. Voz Proletaria.

Voz Proletaria. (28 de mayo de 1964). La Denuncia de la Semana. Voz Proletaria .

Voz Proletaria. (28 de mayo de 1964). Las concesiones petroleras son las "repúblicas independientes". Voz Proletaria.

Voz Proletaria. (30 de julio de 1964). Denuncian guerra bactereológica en Riochiquito. Voz Proletaria.

Voz Proletaria. (30 de Julio de 1964). En encuentro con guerrilleros, perecen 3 elementos del ejército. Voz Proletaria.

Voz Proletaria. (30 de julio de 1964). Esto es la acción civico militar: presos, asesinatos y torturas en regiones campesinas de Marquetalia. Voz Proletaria.

Voz Proletaria. (30 de julio de 1964). Genocidio Oficial en Riochiquito. Voz Proletaria.

Voz Proletaria. (30 de julio de 1964). Se pide a los parlamentarios denunciar crimen contra Marquetalia. Voz Proletaria. 